\title{
MEDIATION IN GUARDIANSHIP PROCEEDINGS FOR THE ELDERLY: AN AUSTRALIAN PERSPECTIVE ${ }^{1}$
}

\section{Robyn Carroll* and Anita Smith**}

Recognition of the benefits that mediation offers to litigants and to the court and tribunal systems has led to formal recognition and institutionalization of the process in Australia, Canada, the USA and many other countries. In many instances, these benefits include flexibility of process, informality, a more conciliatory approach to dispute resolution and reduced costs to parties. Some of these benefits, when compared to more traditional and adversarial court processes, have also flowed from the introduction of tribunals in many jurisdictions, including guardianship. Guardianship proceedings in Australia are by tribunals, not courts, and they use flexible procedures, are generally timely, informal, non-adversial and rarely involve extensive legal costs. In applications made pursuant to guardianship legislation in Australia, guardianship tribunals are required to consider the wishes of the person about whom a guardianship application is made, find the outcome that is the least restrictive of that person's freedom of decision or action and make decisions that are in the best interests of that person. In this tribunal environment a number of questions arise regarding the use of mediation in guardianship proceedings. Firstly, if the process is already efficacious and inexpensive, do the usual inducements for using mediation arise? Secondly, effective mediation requires that one party is not at a significant disadvantage to another during the mediation process. What measures, if any, are in place to ensure that an elderly person with a disability is able to participate in mediation in a meaningful way? Thirdly, given the legislative principles to be applied by guardianship tribunals once an application is before them, is it ever appropriate that an application be resolved by consensus between the parties and if so, when? This article addresses these questions and other issues that need to be addressed if mediation is to play a larger role in resolving guardianship issues.

La reconnaissance des bénéfices qu'offre la médiation aux parties en litige ainsi qu'aux cours et aux systèmes de tribunaux a mené

1 This is a revised version of a paper that was presented to the Canadian Conference on Elder Law and International Guardianship Network, Vancouver, 13-15 November 2009 and the Australian Guardianship and Administration Conference, Brisbane, 19-20 March 2009. The authors wish to thank the reviewers for their helpful comments in preparing this article for publication. Please note that the views expressed by the authors in this article are their own views and are not presented as the views of the Tribunals of which they are members.

* Professor, Law School, The University of Western Australia, and Sessional Member of the Western Australian State Administrative Tribunal.

** President, Guardianship and Administration Board, Tasmania, Australia. 
à la reconnaissance formelle et l'institutionnalisation du processus en Australie, au Canada, aux Etats-Unis et dans plusieurs autres pays. Dans beaucoup de cas, ces bénéfices comprennent la souplesse du processus, l'absence de forme, une approche plus conciliante à la résolution de différends et des coûts réduits pour les parties. Certains de ces bénéfices, lorsque l'on fait la comparaison avec les processus plus traditionnels et accusatoires des cours, ont aussi découlé de la mise en place dans plusieurs pays de tribunaux, y compris des tribunaux de tutelle. En Australie, les instances de tutelle ont lieu devant des tribunaux et non des cours; on y utilise des procédures souples, ils sont généralement assez rapides, sans formalités, sans recours à la confrontation, et entraînent rarement des coûts légaux élevés. Lorsqu'une requête est faite conformément à la législation sur la tutelle en Australie, les tribunaux de tutelle doivent tenir compte des désirs de la personne visée dans la requête, identifier le résultat qui restreint le moins la liberté de décision et d'action de cette personne et faire des décisions conformes à l'intérêt véritable de cette personne. Dans ce contexte de tribunaux, un nombre de questions se présentent quant à l'utilisation de la médiation dans des instances de tutelle. D'abord, si le processus est déjà efficace et pas cher, les incitations habituelles à l'utilisation de la médiation se présentent-ils? Deuxièmement, pour que la médiation soit efficace, il ne faut pas qu'une des parties soit en position désavantageuse par rapport à l'autre pendant le processus de médiation. Quelles mesures, s'il y en a, sont en place pour assurer qu'une personne âgée ayant une déficience puisse participer à la médiation de façon significative? Troisièmement, vu les principes légaux qui doivent être appliqués par les tribunaux de tutelle lorsqu'ils sont saisis d'une requête, est-ce jamais approprié qu'une requête soit résolue par consentement entre les parties, et si oui, dans quelles circonstances? Cet article traite de ces questions et d'autres questions à considérer si la médiation va jouer un plus grand rôle dans la résolution de problèmes de tutelle.

\section{INTRODUCTION}

Mediation is a popular method of dispute resolution that has become a regular feature of legal practice. Once titled "alternative," mediation is now a mainstream process in many areas of the law in Australia and other common law jurisdictions. ${ }^{2}$ Increasingly, legislation and court procedures provide for media-

2 For leading texts in Australia, see Hilary Astor \& Christine M. Chinkin, Dispute Resolution in Australia, $2^{\text {nd }}$ ed. (Sydney: Lexis Nexis Butterworths, 2002); Laurence Boulle, Mediation, Principles, Process, Practice (Sydney: Butterworths, 1996); Tanya Sourdin, Alternative Dispute Resolution, $3^{\text {rd }}$ ed. (Pyrmont: Lawbook Co, 2008); David Spencer \& Michael Brogan, Mediation Law and Practice (Cambridge: Cambridge University Press, 2006). For Canada and the USA see 
tion before a hearing is conducted, and in some cases, before court proceedings can be commenced. ${ }^{3}$ Mediation is not only used within the court system. Specialized tribunals in jurisdictions such as anti-discrimination, workers' compensation and industrial relations use mediation, conciliation and other facilitative processes. These processes have many benefits, including increased party satisfaction, ${ }^{4}$ reductions in court and tribunal waiting lists and reduction in the costs associated with litigation for parties. ${ }^{5}$

In Australia, guardianship applications are dealt with by tribunals, not courts. ${ }^{6}$ Yet despite the growing use and popularity of mediation and other facilitative processes within tribunals in Australia, ${ }^{7}$ most guardianship applications are adjudicated and mediation is used infrequently. ${ }^{8} \mathrm{~A}$ recent informal email survey

Julie Macfarlane, Rethinking Disputes: the Mediation Alternative (Toronto: Emond Montgomery, 1997); Christopher Moore, The Mediation Process: Practical Strategies for Resolving Conflict (San Francisco: Jossey-Bass, 2003); Steven Goldberg, Frank Sander \& Nancy Rogers, Dispute Resolution: Negotiation, Mediation and other Processes, $2^{\text {nd }}$ ed. (Boston: Little Brown, 1992); Kimberlee Kovach, Mediation: Principles and Practice (St. Paul: West Pub. Co., 1994).

3 Proceedings relating to children cannot be brought in the Family Courts in Australia unless an attempt has been made to settle the dispute by mediation or there are circumstances exist as provided by s. 60I Family Law Act 1975 (Cth).

4 For a study evaluating plaintiffs' perceptions of the dispute resolution processes in the New South Wales District Court's Sydney Registry and in private mediation through the New South Wales Law Society mediation program see Mary Delaney \& Ted Wright, Plaintiffs' Satisfaction with Dispute Resolution Processes: Trial, Arbitration, Pre-trial Conference and Mediation (Sydney: Justice Research Centre and Law Foundation of New South Wales, January 1997).

5 For an extensive review of ADR research in Australia and New Zealand, see Sourdin, supra note 2 at Alternative Appendix G; and Australian Law Reform Commission Issues Paper 25: Review of the Adversarial System of Litigation. ADR - Its Role in Federal Dispute Resolution (Sydney: ALRC, June 1998).

6 Research has demonstrated the various strengths of Australia's guardianship panels when compared to regimes which utilise courts, see Terry Carney \& David Tait, The Adult Guardianship Experiment: Tribunals and Popular Justice (Sydney: The Federation Press, 1997). Carney has since noted that "[S]ometimes, as in Canada and Europe, there are constitutional reasons why a court must be selected. In other cases the choice rests on the (closely analogous) argument of principle that it is wrong to permit fundamental rights to be varied by a body other than a court. On other occasions, courts are chosen simply because they were the body which historically did this work." Terry Carney, "Challenges to the Australian Guardianship and Administration Model” (2003) 2 Elder Law Review 1 at note 62. In Australia; New South Wales, South Australia and Tasmania have specialist 'stand alone' guardianship tribunals, in Victoria, Western Australia, the Australian Capital Territory and Queensland, "omnibus" style tribunals adjudicate guardianship matters. The practice in "omnibus" tribunals has been to retain dedicated members to a particular list (in some cases merged with compatible jurisdictions such as discrimination), so they retain specialist qualities. The Northern Territory continues to use lower courts for guardianship matters.

7 For example, Maurice Spillane, "Mediation in the State Administrative Tribunal: From Alternative to Mainstream A Success Story" (Paper presented to the $9^{\text {th }}$ National Mediation Conference, Mediation: Transforming the Landscape, Perth, Western Australia, 10-12 September 2008), online: National Mediation Conference <http://www.mediationconference.com. au/2008_Papers/SpillaneMaurice.docl> (last accessed 20 January 2009).

8 Similarly, conciliation and other facilitative processes such as compulsory conferencing are not commonly used to resolve guardianship applications. While there are important distinctions between these processes, the term mediation is used in a general way in this article to encompass facilitative processes where the matter is not resolved by adjudication. 
of Australian guardianship tribunals conducted by the authors found that in an annual national case load of approximately 25,000 guardianship and administration applications in the 2006-7 reporting year, fewer than 20 applications per year were mediated within those systems. ${ }^{9}$ These figures indicate that far less than $1 \%$ of guardianship applications are being mediated within the tribunal system: the vast majority being adjudicated following a hearing. This raises significant questions about the reasons underlying the choice of process for guardianship applications in Australia, particularly in light of the growing interest in mediation involving people with disabilities, the elderly and guardianship issues. ${ }^{10}$

This article examines the reasons why adjudication remains the principal method of dealing with guardianship applications in Australia. It focuses primarily on applications concerning the elderly but the analysis and conclusions it presents can be applied to guardianship applications more generally. We conclude that while mediation offers benefits to an elderly person and to parties concerned for them, there are two broad explanations for the infrequent use of mediation in guardianship applications in Australia. The first explanation lies in the concern that the nature of the jurisdiction, aimed at the protection of people with decision making disabilities through the appointment of substitute decision makers, is not always suited to mediation. People to whom guardianship applications relate are, by definition, people who have or are suspected of having impaired capacity to make decisions. Participation in a mediation process assumes that the parties have capacity to negotiate, make decisions and enter

9 An email was sent to each Australian tribunal exercising guardianship and administration jurisdiction on Wednesday, 17 September 2008 seeking a response to two questions: (1) whether they have formal alternative dispute resolution policies; and, (2) how often tribunal proceedings relating to guardianship applications are diverted into mediation rather than adjudication?

10 In Australia, see Jim Simpson, "Alternative Dispute Resolution and People with Disabilities" (2003) 14 Australian Dispute Resolution Journal 31; and Robyn Carroll, "Appointing Decision Makers for Incapable Persons - What Scope for Mediation?" (2007) 17 Journal of Judicial Administration 75 [Carroll, "Appointing Decision Makers"]. In the U.S.A. see B.D. Shannon, "Another Alternative: The Use of Moderated Settlement Conferences to Resolve ADA Disputes Involving Persons with Mental Disabilities" (1996) 12 Ohio St. J. Disp. Resol. 147; Suzanne Schmitz, "Mediation and the Elderly: What Mediators Need to Know" (1998) 16 Mediation Quarterly 71; A. Frank Johns "Guardianship Adjudication Examined within the Context of the ABA Model Rules of Professional Conduct," (2007-2008) 37 Stetson L. Rev. 243; Susan Gary, "Mediation and the Elderly: Using Mediation to Resolve Probate Disputes over Guardianship and Inheritance" (1997) 32 Wake Forest L. Rev. 397; Mary Radford, "Advantages and Disadvantages of Mediation in Probate, Trust and Guardianship Matters" (2000-2001) 1 Pepperdine Dispute Resolution Journal 241; Mary Radford "Is the Use of Mediation Appropriate in Adult Guardianship Cases?” (2001-2002) 31 Stetson L. Rev. 611[Radford, "Mediation Appropriate"]; Kate Mewhinney, "North Carolina Tries Mediation for Estate and Guardianship Disputes" (2007) 28 Bifocal: Bar Associations in Focus on Aging and the Law 26; Erica Wood, "Dispute Resolution and Dementia: Seeking Solutions" (2000 - 2001) 35 Ga. L. Rev. 785; Eva Soeka, "An Option for Families and Older Adults: Adult Guardianship Mediation” (Mar 2000) 17 ABA: General Practice, Solo and Small Firm Division Magazine 58. Also see Susan Hartman, Adult Guardian Mediation, 7 The Centre or Social Gerontology, Best Practice Notes (Sept 1996) online: The Centre for Social Gerontology <http://www.tcsg.org/ bpnotes/sept96/adult.htm> (accessed 20 Jan 2009); The Centre for Social Gerontology), Elder Mediation and Aging, online: The Centre for Social Gerontology <http://www.tcsg.org/med. htm> (Last updated January, 2009.) (Accessed 20 January 2009). 
into agreements that meet their best interests. Engaging a person with impaired decision making or suspected impaired decision making in a process of this nature often will be inappropriate. Even where the parties to a mediation do not include the person with impaired decision making, for example family members and service providers, significant issues can arise about the efficacy and legitimacy of agreements made by them. ${ }^{11}$

Second, the informal and inquisitorial nature of the guardianship tribunal application and hearing process, which has removed most of the combative and adversarial features of traditional court proceedings, has largely rendered the need for an "alternative" approach unnecessary from the perspective of costs or timeliness and, to some extent, from a therapeutic perspective. ${ }^{12}$ This is not to say that mediation cannot be of great benefit when addressing the many conflicts that can arise where an adult lacks or loses decision making capacity. In the Australian guardianship system, however, it is more likely to be used as a "bookend" to the determination of a guardianship application. That is, mediation may occur either before an application is made, avoiding the need for adjudication, or it may follow a tribunal decision, which may involve the appointment of a substitute decision maker. In the latter case a guardian or administrator may decide that the best way to resolve outstanding or emerging issues relating to the person with a disability is to use mediation.

As the aim of this article is to highlight the reasons why mediation has only a limited role to play in this jurisdiction in Australia, as well as the potential for mediation to be used to resolve elder disputes, some introductory comments about mediation are made in the Introduction. Then, by way of background to the jurisdiction, we examine in Part II the characteristics of complex guardianship disputes concerning the elderly and in Part III, we overview the legislative framework of Australian guardianship proceedings and the current use of mediation. In Part IV we identify the distinctive features of guardianship applications that have implications for the choice of process for dealing with applications. Finally, in Part V of this article, we identify a number of issues relevant to the use of mediation in dealing with guardianship applications and guardianship disputes more generally before presenting our conclusions.

Mediation can be defined as

a process in which the parties to a dispute, with the assistance of a dispute resolution practitioner (the mediator), identify the disputed issues, develop options, consider alternatives and endeavour to reach an agreement. The mediator has no advisory or determinative role in regard to the content of the dispute or the outcome of its resolution, but may advise on or determine the process of mediation whereby resolution is attempted. ${ }^{13}$

11 For analysis and critique of these concerns, see Radford, "Mediation Appropriate," ibid.

12 See further, Carroll, "Appointing Decision Makers" supra note 10

13 National Alternative Dispute Resolution Advisory Council (NADRAC), Dispute Resolution Terms, online: Government of Australia, 2003 <http://www.nadrac.gov.au/www/nadrac/ 
By definition, a mediator has a facilitative role as distinct from an advisory or determinative role. ${ }^{14}$ The mediator does not advise the parties on the terms of their agreement or decide how the issues will be resolved. The mediator manages the processes and makes decisions about the best way to apply the process, for example: who should be present at the mediation, whether the parties should meet separately with the mediator and whether the mediation should be adjourned or terminated. The role of the mediator in relation to the outcome of the mediation is, therefore, fundamentally different from that of a tribunal member whose role is to determine the matters before it after consideration of the evidence and party submissions. There is some similarity, however, between the role of the mediator as process manager and the role of a judge or tribunal member who has the power to determine how the hearing will be conducted.

There are many distinctive features of mediation and other facilitative processes. ${ }^{15}$ Arguably the two most significant differences between mediation and determinative tribunal processes are, first, the ability in mediation to focus on relationships and people rather than facts, evidence and rights, and second, the consensual and participatory nature of mediation. Regarding the first difference, parties in mediation are encouraged to look at outcomes that will meet the needs, or interests, of both of the parties, as well as the interests of others affected by the dispute. Unlike determinative processes, mediation is not a process by which parties' rights are determined and where, in a dispute, the outcome is essentially a win for one party and a loss for the other. Regarding the second difference, in mediation the parties decide the terms on which the dispute will be resolved: the outcome is not imposed upon them by an adjudicator. The fact that they are able to determine the outcome empowers the parties individually and collectively to make decisions on matters affecting their lives. In many situations, the parties are in the best position to make the necessary decision. While consent is a defining feature of mediation, this is not so for determinative processes. With these two key features in mind, other differences and similarities between the mediation and determinative tribunal processes will be noted in Part IV, below.

\section{CHARACTERISTICS OF GUARDIANSHIP DISPUTES CONCERNING THE ELDERLY ${ }^{16}$}

Guardianship applications are brought because decisions need to be made on behalf of a person with a disability. It is not uncommon for there to be conflict between the various support persons of the person with a disability. Indeed the presence of conflict about a significant life or financial decision on behalf of a person with a disability can increase the likelihood that a decision maker will need to be appointed. The tribunal can appoint a person representing one view-

rwpattach.nsf/VAP/(960DF944D2AF105D4B7573C11018CFB4) 1Report8_6Dec. doc/\$file/1Report8_6Dec.doc> at 9 .

14 The terms "advisory process" and "determinative process" are defined by NADRAC. Ibid.

15 See e.g. Boulle, supra note 2 at 35 for discussion of the features of mediation that lends it to guardianship issues see the references in note 11.) See further Sourdin, supra note 2 at Ch. 3.

16 In this Part, the authors draw on their experience as guardianship tribunal members to make a number of observations about guardianship applications for the elderly. 
point or another where it finds that one particular viewpoint has been proven to represent the best interests of the incapacitated person.

The majority of applications to guardianship tribunals for the appointment of a substitute decision maker are straightforward and uncontested. There may be general agreement among people concerned with the person with a disability that there is a lack of capacity, a need for an appointment and for what functions, and about who is best placed to assume the decision making role. In some cases, however, an application will be attended by high levels of conflict between parties to the application, high levels of animosity and hostility and deep family divisions. Typically, some level of family conflict predates the application and the issues before the tribunal inflame the conflict. While most applications do not become adversarial and protracted, it is not so much the nature of the decision to be made but the attitudes of the parties that can determine how an application proceeds.

Some characteristics of these disputes are readily identifiable and serve as predictors to whether the resolution process is likely to be protracted. It is in these particularly hostile cases that the ability to reduce the impact of the conflict and address some of the underlying causes of the conflict is most important. The most common causes of hostility, in the authors' experience, are as follows:

\section{A. Altruism}

When a person acquires a decision making disability after an active and purposeful life, their circumstances may evoke empathy, sympathy and pity in others. The inability of the previously capable person to make or articulate their own decisions creates a vacuum into which others (well meaning or otherwise) place their own interpretations of the person's best interests. A common feature of protracted disputes in guardianship is where there are competing standards of altruism, with parties being polarized as "pragmatists" or "do-gooders." Combative protests such as 'I am only doing what Mum wanted,' or 'I just want what's best for ...' often preface a self serving statement to the tribunal. Discerning the difference between altruism and self interest is a live issue before guardianship tribunals.

\section{B. Blended families}

The rate of divorce in Australia has increased significantly since the introduction of no-fault divorce in $1975 .{ }^{17}$ In the same time, de facto marriage relationships have become more common and child bearing unions can be transitory. Coupled with the fact that Australians are living longer than ever, this means that an elderly person may have two or three families, all with competing demands and expectations. They may also be partnered to a person with children from two or three other families who have an interest in the elderly person's wellbeing. These relationships and the interaction between them invariably will affect the

17 See Australian Bureau of Statistics 1301.0 Year Book Australia, 2008, online: ABS <http:// www.abs.gov.au/ausstats/ABS@.nsf/7d12b0f6763c78caca257061001cc588/D5F4805AD4C3 E03ECA2573D2001103E0?opendocument>, (accessed 27 April 2009). No fault divorce was introduced by the Family Law Act 1975 (Cth). 
family dynamics. These dynamics, including patterns of conflict as well as care, inevitably resurface when the progenitor loses capacity to make decisions.

\section{A need for control and authority}

With the passing of privacy laws, ${ }^{18}$ few financial decisions or transactions can be made without formal delegated authority. Not only are financial institutions aware of the need for authority to make decisions and requiring legal appointments of decision makers, but medical practitioners and a range of other service providers are increasingly aware of a need for the clear line of legal authority to provide services or release information. Adult children may have differing views about the source and validity of certain decisions - the classic example being siblings who cannot agree on whether their parent requires residential aged care. When arguments break out, there can be a need for a clear source of authority on any decision, no matter how trivial.

\section{Source of the conflict}

Often the person with the disability has played no recent part in creating the conflict surrounding the application. This is particularly the case for elderly people. While their children, step-children, relatives and friends are engaged in a dispute, it is often the case that the elderly person is entirely unaware that there is any current problem. This may result not only from their cognitive deficits in understanding but also because it has not been brought to their attention or it has been hidden from them in an effort to save them distress. At other times, the conflict may be heightened by the behaviour of the elderly person, albeit unwittingly in most cases. It is frequently a symptom of dementia that a person will be easily influenced, highly suggestible and will give conflicting answers to different parties according to the cues that those people give. Questions like "You don't want to live at a nursing home do you?" or "You know you can't cope at home any more don't you?" may elicit contradictory answers. In many guardianship applications the conflict has little to do with the person with a disability and everything to do with intra family conflict and conflict between the family and service providers.

\section{E. Money}

There is no doubt that a significant factor in elevating the level of conflict surrounding a guardianship application is the presence of substantial amounts of money, either in debit or in credit. Where the represented person has very large debts, the conflict is "person centred" and the presence of substantial debt is a source of stress to the person with a disability and those who care for them. However, a relatively wealthy person can attract conflict which is not "person centred" but usually diffuse and multi-party. In this situation, families may see their rich elderly relative or "friend" with a disability as a source of inheritance. Parties may also be motivated by uncertainty about who will inherit and therefore attempt to secure money from the estate inter vivos to avoid uncertainty in a will. This inevitably leads to conflict. What is seen as a "substantial amount"

18 See e.g. the Privacy Act 1988 (Cth). 
worthy of disputation by family members will depend upon the relative wealth of the rest of the family. In some cases the mere receipt of a pension can be motivation enough for persons to interfere with financial arrangements to their own ends. Where a person is wealthy by objective standards it is more likely that parties will be legally represented. In this case proceedings are more likely to be protracted and the parties' decision to involve lawyers may heighten the hostility between the parties.

\section{F. Allegations of abuse and exploitation}

If they are incapable or arguably incapable of making reasonable decisions, people with disabilities are more vulnerable to abuse and exploitation. Principles of natural justice confer on a person accused of abuse or exploitation rights to deny and refute any allegations. The nature of the accusations and process of countering them can significantly elevate the level of conflict in proceedings. Allegations of abuse and exploitation may give rise to legal consequences beyond the jurisdiction of the tribunal, including civil and criminal proceedings. While the allegations will not necessarily be proved or disproved by the guardianship proceedings, their presence usually indicates to a tribunal the need to appoint an independent statutory officer as guardian, to ensure that evidence of the abuse or exploitation is appropriately collected and that decisions about reporting to relevant authorities are made impartially.

\section{G. Disputes of long or short standing}

Sometimes disputes surrounding an application will be recent. This is most likely to be the case where there has been a sudden change in the life circumstances of the person with the disability, for example the loss of a carer or a change in financial circumstances. In other cases the conflict may arise between parties who have known each other for many years and have long standing grievances which are unrelated to the application. Guardianship tribunal members and staff are well aware that many applications become a vehicle through which dysfunctional family members play out longstanding sibling rivalries and unresolved grief issues connected with the elderly person. In both cases it is important for the guardianship proceedings to focus on the future of the represented person rather than on past events or impressions. The older the dispute the less likely it will be related to the application or that it will be resolved by the guardianship proceedings.

\section{OVERVIEW OF AUSTRALIAN GUARDIANSHIP LAW AND PROCESSES}

Although Australian guardianship tribunals were developed originally for people with intellectual disabilities, ${ }^{19}$ they have become, almost by default, a major adjudicator of elder law issues. The guardianship system in Australia has

19 This model was initially developed in Victorian Government, Report of the Minister's Committee on Rights and Protective Legislation for Intellectually Handicapped Persons (Melbourne: Victorian Government Press, 1982) [The Cocks Committee Report]. 
developed in the knowledge and awareness of the characteristics of guardianship disputes concerning the elderly identified in the previous Part. Some understanding of the legislative history and framework of guardianship law and process is necessary to understand the existing guardianship system in Australia. This Part provides an overview of the jurisdiction. ${ }^{20}$

Two features distinguish Australian guardianship systems from their historical bases $^{21}$ and international counterparts. The first is a separation between personal decision making (for which "guardians" are appointed) and financial decision making (for which "administrators" or "financial managers" are appointed). ${ }^{22}$ The second feature is that appointments of guardians and financial managers are made by specialist tribunals ${ }^{23}$ (or specialist lists within multi-jurisdictional tribunals ${ }^{24}$ ) created by legislation passed since the 1980s. ${ }^{25}$ Guardianship tribunals also exercise a supervisory role over privately appointed decision makers such as enduring guardians and donees of enduring powers of attorney and determine applications to amend or revoke private appointments, for example, if the appointed donee of the power is not acting in the best interests of the person with a disability.

Applications before tribunals often relate to the transition from independence to supported accommodation by an elderly person who has acquired dementia and can no longer make reasonable decisions for himself or herself. The need for an appointment can arise from personal issues (such as resisting a change in accommodation due to a lack of insight into the need for assistance), or from financial issues (such as sale of the person's home and funding the costs of resi-

20 For further detail see Anita Smith, "History and Operation of Australian Guardianship and Administration Laws" in Kees Blankman, ed. International IGN Conference on Guardianship Conference Book (Bergen: Universiteit Amsterdam, 13 September 2008 )

21 For the history and development of Australian guardianship laws, see Carney \& Tait, supra note 6.

22 For ease of reference we will refer to both areas of decision making in the Australian jurisdiction as "guardianship" applications, unless otherwise indicated. In most North American jurisdictions a guardian appointed by a court is essentially a financial manager. This is consistent with European models as well where wardship or guardianship denotes a system of primarily financial control. Sweden uses the term "administrator" in this field also, but it relates to the level of control required rather than the subject matter of the substitute decisions.

23 Guardianship and Management of Property Act 1991 (ACT) ; Guardianship Act 1987 (NSW), Part 6 establishes the Guardianship Tribunal; Guardianship and Administration Act 1993 (SA), Part 2 establishes the Guardianship Board; Guardianship and Administration Act 1995 (Tas), Part 2 establishes the Guardianship and Administration Board. The Northern Territory legislation makes provision for a Guardianship Panel to be set up when a guardianship application is received, Adult Guardianship Act 1988 (NT), section 9.

24 ACT Civil and Administrative Tribunal Act 2008 (ACT) establishes the Civil and Administrative Tribunal; the Queensland Civil and Administrative Tribunal Act 2009 (Qld) establishes the Civil and Administrative Tribunal; the Victorian Civil and Administrative Tribunal Act 1998 (Vic) which establishes the Victorian Civil and Administrative Tribunal; the State Administrative Act 2004 (WA) which establishes the State Administrative Tribunal;

25 The Northern Territory (NT) has a unique approach which has been the subject of numerous proposals for reform to achieve national uniformity. Although the NT legislation has been introduced since the 1980s it does not follow the post 1980's Australian approach to guardianship laws and therefore in this article, references to a national approach will not usually include the NT. 
dential aged care and management of the estate). Despite a possible lack of capacity, the person with the disability is a central party to the proceedings and expected to be present and participate to the extent they can. Tribunals ensure the involvement of disability advocates, interpreters and in some complex cases legal representatives (or amicus curiae) to ensure that the person with a disability can participate as fully as possible.

The legislation in each Australian state sets out the principles to be applied in decision making and the determination of applications concerning a person with a disability. The principles are the same in the Northern Territory, Victorian and Tasmanian Acts and exist in similar form in the legislation in the other jurisdictions. ${ }^{26}$ The core principles are that:

(a) the means which is the least restrictive of a person's freedom of decision and action as is possible in the circumstances is adopted;

(b) the best interests of a person with a disability are promoted; and

(c) the wishes of a person with a disability are to be given effect wherever possible.

How these principles are balanced against each other differs in every guardianship application. While the "best interests" principle allows for a paternalistic approach, the competing and equally weighted principles of freedom of decision and action and the person's wishes can ensure an active consideration in each matter that goes beyond paternalism. Such principles have led tribunals to consider applying the principle of personal dignity and "dignity of risk," even though the risk might be a risk of death or injury. ${ }^{27}$ It is a notable advantage of the Australian guardianship system that the views of the person with a disability can be obtained by the tribunal by a number of means: by a report of an interview with trained tribunal staff, by a representative of the Public Guardian or similar public body, or through their participation in the hearing. Often the interview or the hearing will be the first time that an impartial person has sought his or her views.

Tribunal members usually sit as single members or multi-disciplinary panels of three and come from various disciplines, including law, medicine, finance, social work and welfare. Legal representation is not common in Australian guardianship proceedings, largely because the tribunal manages the proceedings which are inquisitorial in nature and in part because costs are not usually awarded. When legal representatives are engaged their role does not reflect traditional

26 Guardianship and Management of Property Act 1991 (ACT) s 4; Guardianship Act 1987 (NSW) s4; Adult Guardianship Act 1988 (NT) s4; Guardianship and Administration Act 2000 (Qld) ss5,6,7; Guardianship and Administration Act 1993 (SA) s5; Guardianship and Administration Act 1995 (Tas) s5; Guardianship and Administration Act 1986 (Vic) s4; Guardianship and Administration Act 1990 (WA) s4.

27 See for instance BWV [2003] VCAT 121 (28 Feb 2003) and Gardner re BWV[2003] VSC 173ER [Guardianship Application] 1.10 .08 online: Government of Australia <www.guardianship.tas. gov.au/decisions/guardianship> 
advocacy roles. For instance, cross examination is usually only undertaken with leave of the tribunal. The tribunal takes responsibility, on most occasions, for asking questions. Therefore, rather than having responsibility for presentation of their client's 'case,' legal representatives attend hearings to assist their clients to answer questions, to assist the tribunal with relevant aspects of the evidence and to make submissions.

The availability of publicly funded (or subsidized) independent statutory decision makers (the Public Guardians [variously described] and the Public Trustees) for appointment as a neutral representative for the person with a disability is also of benefit to the guardianship system and to the person with a disability. Where a dispute between the parties is intractable the appointment of the independent guardian or administrator is the appointment that is most likely to ensure that the best interests of the person with a disability are represented impartially and objectively. Being statutory offices, their powers to intervene in and resolve disputes must arise by statute. Most often these powers will be conferred by a formal order of appointment of a tribunal. Most Public Guardians, Public Advocates, Adult Guardians, Protective Commissioners and Public Trustees can only have minor input without a formal order from a court or tribunal. Therefore, to engage the services of these professional substitute decision makers, parties may not be able to avoid using the more formal processes of a tribunal.

A number of the process features of mediation are present in guardianship tribunal proceedings. In particular, the proceedings focus on the interests of the person with a disability and the parties are given an opportunity to participate in the process by giving evidence and sharing their views. The hearing process is applied flexibly - it is not uncommon for hearings to be held where the person whom the application concerns is located, for example at an aged care facility or hospital. The process is future focused as it is concerned with the need for immediate and ongoing orders rather than resolving factual issues or disputes from the past. Further, many of the skills and strategies employed by mediators to empower the parties, to facilitate communication, to shift perceptions, to problem solve and to reality check possible solutions are employed by trained tribunal members during the hearing process. We conclude below that this is one of the key reasons why the mediation process is not often employed to deal with guardianship applications. It remains a distinctive feature of hearings as distinct from mediation, however, that the tribunal, not the parties, determines the outcome of the application.

The level of experience and expertise relating to mediation within guardianship tribunals is variable. Members in multiple jurisdiction tribunals are rapidly becoming experienced as mediators through their involvement in jurisdictions other than guardianship. There is likely to be greater willingness to use mediation and other facilitative processes where they are shown to be effective in reducing the number of hearings and the length of proceedings. The more experienced tribunals and their members become with mediation, the more likely they are to consider whether mediation will be of benefit to the parties in guardianship matters. It is possible that Tribunal members who sit across a range of jurisdictions and who mediate in their capacity as a member in those jurisdictions will be more likely to refer matters to mediation than a member who only hears guard- 
ianship applications and is not trained or experienced in mediation either within the tribunal or outside. It remains to be seen, however, whether the increased use of mediation within tribunals generally will lead to a significant increase in the number of guardianship applications referred to mediation.

\section{KEY FEATURES OF GUARDIANSHIP TRIBUNAL APPLICATIONS}

In Part II we identified common causes of conflict surrounding guardianship applications and in the previous Part we have overviewed the Australian guardianship system: jurisdiction, process and legislative principles. The challenge for any guardianship system is to ensure that when disputes arise about the best interests of a person with a disability that those are properly addressed and protected, while maximising the opportunity for less restrictive alternatives to be put in place. There are features of the guardianship jurisdiction that renders it unique within the legal system. Understanding these distinctive features, set out in this Part, allows us to appreciate some of the reasons why mediation may be unsuitable or unnecessary in this jurisdiction.

\section{A. A protective jurisdiction}

Historically guardianship has been understood as a 'protective jurisdiction'28 in which the law seeks to achieve a balance between principles that on the one hand protect a person with a decision making disability from neglect, abuse and exploitation and on the other hand protect their liberty and autonomy. The legislative principles applied to decisions made by guardianship tribunals and the inquisitorial nature of the proceedings reflect the protective nature of the jurisdiction and the responsibility of the state to ensure that effective and legitimate decisions are made on behalf of a person who is not able to make decisions on their own behalf. The guardianship jurisdiction is not an area of private law capable of resolution by the parties. Once a tribunal is seized of responsibility to determine an application, any decision to withdraw or discontinue the application must be made according to the best interests of the person who is the subject of the application. Parties are not free to enter into agreements to withdraw an application without the approval of the tribunal. Neither are parties free to determine how an application will be run or to define the issues. The tribunal decides the issues and is responsible for ensuring procedural fairness.

\section{B. Capacity is a threshold issue}

Capacity is a threshold issue for establishing jurisdiction. This means that tribunals need to be well equipped to receive evidence concerning a person with a disability. Being well equipped means receiving the best possible evidence about the person with a disability in a manner that is "real" as opposed to "tokenistic." Tribunal members are also required to make efforts to obtain and give effect to the views or wishes of the person with a disability even where there is evidence

28 For a brief historical background to the Australian guardianship jurisdiction see Carney \& Tait, supra note 6 in chapter 2 where it is noted that on settlement of the Australian colonies, lunacy powers were given to the superior courts of the Colonies. at 11 . 
that they lack capacity to make reasonable decisions. A person's wishes can be realistically accommodated by, for instance, providing for early review of an order, placing certain conditions in an order or taking into account the nature of the relationship between the person with a disability and the proposed appointee.

The need to decide capacity means that proceedings can be quite confronting for the parties as issues of disability and capacity are discussed openly in the presence of the elderly person at the centre of the proceedings. In a society where attitudes to disability are still evolving, some observers can be disturbed and alarmed about such discussions. Tribunal members strive to develop means of discussing such considerations with tact and openness and in a manner that is respectful of the parties.

In contrast, mediation operates on the assumption that the parties are competent and have the capacity to participate in the process and consent to agreed outcomes. There is a danger that this assumption will be applied inappropriately to guardianship matters and insufficient allowance made for the limitations on participation and self-determination that arise when the person the subject of the mediation has limited decision making capacity. A person with a disability may be at a distinct disadvantage as a participant in the mediation process or as the subject of the process without the observance of the statutory rights and principles (such as a right to representation and observance of their wishes) that are applied in tribunal proceedings. Further, parties to mediation may not be prepared to include the person with a disability and may be unable to conduct an effective interview with a person with a disability and report in an impartial and skilled manner.

\section{Privacy and confidentiality}

While guardianship proceedings are generally conducted in open hearings, publication of details about a person who is the subject of guardianship proceedings is not permitted. ${ }^{29}$ As the number of parties to proceedings is usually small and there are few observers to guardianship proceedings, in practice, similarly to mediation, the proceedings in the tribunals are relatively private.

Guardianship tribunals have the ability to require the production of personal and financial records that otherwise would be protected by privacy laws and privilege. This is extremely important for obtaining medical reports about a person's capacity. A medical practitioner is usually bound by medical professional privilege and cannot divulge medical information about a person without their consent. If by reason of their disability, a person's ability to give informed consent is impaired, there are obvious difficulties in obtaining the necessary medical or financial information. Tribunals have the authority to require disclosure by parties who otherwise would be bound to keep such information confidential. Without legislation, the power to compel evidence is not available to mediators. Parties to a mediation process are unlikely to have the legal authority to demand medical evidence and other background information that may be critical

29 E.g. Guardianship and Administration Act 1995 (Tas) s13 Guardianship Act 1987 (NSW) s57; Adult Guardianship Act (NT) s26. 
to issues and agreements between the parties.

\section{Expert witnesses and impartiality}

The question of a person's capacity to make reasonable judgments is most often decided on the basis of expert opinion from a medical practitioner, a neuro-psychologist or a person with relevant expertise. In an adversarial setting opposing parties seek opinions from alternative specialists to support their arguments. This has a number of effects; first, seeking a variety of reports can be costly. Second, certain experts eventually become labeled as being "pro" or "anti" certain positions which dilutes the credibility of their evidence, rendering it of little assistance to tribunal decision making. One advantage of the inquisitorial process is that the opinion is tested by the tribunal itself. A variety of different factors can be assessed, such as the length of the relationship between the practitioner and the level of specialisation that he or she has. Having the tribunal direct questions to an expert witness saves time and money compared with the adversarial approach. It also preserves the impartiality of expert witnesses as there can be little room for an accusation that the expert is tailoring their evidence according to the person who hired them.

\section{E. Cost and Timeliness Imperatives}

Australian tribunals collectively decide around 25,000 applications per year. ${ }^{30}$ Ninety-five percent of these applications are heard and determined within 45 days of receipt. ${ }^{31}$ Although there are applications that come before Australian guardianship tribunals which are protracted, highly adversarial and costly, this is not the norm. The majority of cases are decided in a practical, inquisitorial manner and without strong objection. Costs awards are extremely rare in guardianship proceedings and it is usually the case that, if a party has hired legal representation, they meet their own costs. In part this is because it is usually difficult to identify "winners" and "losers" for the purposes of applying costs principles. ${ }^{32}$ The tribunals are funded by Government and there is no fee for making an application. Tribunal time is not charged to the parties except in extremely rare or vexatious cases. It is fair to conclude, therefore, that tribunals generally operate in a timely manner and at low cost to the parties and the public.

\section{MEDIATION: IMPLICATIONS FOR GUARDIANSHIP TRIBUNALS}

There is little doubt that in appropriate cases the mediation process can be used for the benefit of the elderly. ${ }^{33}$ Professor Radford concludes that, for many

30 This figure is aggregated from the annual reports of guardianship boards, lists, courts and tribunals in each Australian jurisdiction for the 2007-2008 year.

31 This derived from the annual reports of guardianship boards, lists, courts and tribunals in each Australian jurisdiction for the 2007-2008 year and from jurisdictional reports submitted twice yearly to the Australian Guardianship and Administration Council.

32 See for instance: Guardianship and Administration Board (Hobart), Reasons for Decision on Costs Application HDH (Costs) 24.10.05 and KSLQ (Costs) 20.12.07 online: GAB <www. guardianship.tas.gov.au/decisions/procedural>

33 See references cited supra note 10. 
reasons, "mediation seems to be a beneficial way of resolving disputes in adult guardianship cases." ${ }^{34}$ She recognizes, however, that:

The use of mediation in adult guardianship must not be wholeheartedly embraced without a critical assessment of its potential to deny the adult the procedural and substantive due-process rights that a formal, adversarial guardianship proceeding is designed to protect. Serious consideration must be given as to how to ensure that the rights of the adult remain the focal point of the mediation. ${ }^{35}$

This passage highlights two key points. First, that the benefits of mediating guardianship issues, in some jurisdictions, are judged by comparison to formal, adversarial proceedings. Second, that the guardianship jurisdiction is concerned with the protection of the rights of adults with decision making disabilities. The second point is common to most jurisdictions. The first is a point which, for reasons outlined in this article, is less applicable to Australia.

\section{A. Reasons why mediation is not often used to resolve guardianship applications}

Although mediation has become popular in most areas of the Australian legal system and has been accepted as part of Australian legal culture, in guardianship matters it is not used often to decide the outcome of an application. ${ }^{36} \mathrm{We}$ conclude that there are two broad explanations as to why mediation is not commonly used in Australian guardianship tribunals. ${ }^{37}$

\section{The "unsuitability" explanation}

A judgment as to the suitability of a matter for mediation needs to be made in every case. ${ }^{38}$ A matter may be unsuitable for a number of reasons. Some reasons will be specific to the case, for example where there is evidence that the process will pose a risk of abuse or harm to a party. Other reasons are more universal, for example the incapacity of the parties to participate in mediation or the need for an authoritative order. ${ }^{39}$

34 Radford, "Mediation Appropriate" supra note 10.

35 Ibid. at 686.

36 See supra note 9 and accompanying text.

37 These conclusions and other commentary are based on analysis and experiences of mediation and the guardianship jurisdiction, not on empirical data. There is a need, identified by a number of commentators, for empirical studies to test hypotheses about the benefits of mediation in this jurisdiction and to evaluate of the functioning and change of guardianship proceedings. For a range of issues in need of further consideration see Simpson, supra note 10; Wood, supra note 10 at 833 .

38 For case study examples see Carroll, “Appointing Decision Makers" supra note 10 at 88-90.

39 Radford categorises the arguments against the use of mediation in adult cases as incompatible with the nature of decision making in guardianship applications, the lack of protection of the adult both procedurally and substantively and the fact that mediation is grounded in selfdetermination. Each of these arguments are analysed and responded in Radford, "Mediation Appropriate," supra note 10. 
One example of unsuitability is where the question to be resolved is whether a person is incapable, by reason of a disability, of making reasonable decisions. This question is central to all guardianship proceedings but is not a matter that can fairly be resolved by agreement between the parties (though the parties' evidence on the question of capacity is taken into account by a tribunal in determining the question of capacity.) It is inimical to the best standards of medical and psychological professional practice (and would hark back to the "bad old days" prior to the Lunacy Acts where relatives could decide such questions) that this question can be resolved by the parties. ${ }^{40} \mathrm{It}$ is also not something that can be resolved by agreement with the person whose capacity is in issue. It illogical to accept the assertion: "I agree that I do not have capacity to make decisions which have legal effect." The situation will be different where the question of incapacity has previously been decided. In this case mediation may be suitable as there may be scope for resolving other issues concerning the incapable person that can be resolved by agreement, for example their place of residence. There is also scope for mediation to resolve differences of opinion between experts and to narrow the issues identified in their expert evidence. Although this process is used in complex litigation it is not likely to be warranted, however, as an additional process to a hearing on a cost-benefit analysis in the guardianship jurisdiction, as the tribunals are equipped to make a determination after due consideration of all the evidence.

Guardianship tribunals decide other issues that are not suited to mediation. The power to remove the donee of an enduring power of attorney or to appoint an administrator, for example, is conferred exclusively on guardianship tribunals by legislation and is not a power that can be exercised by family members or other interested parties by consent. While there are benefits of achieving consensus through mediation this can also be achieved in effect, in tribunal proceedings. This leads to the second explanation as to why mediation is not frequently used in Australia to resolve issues arising in guardianship applications.

\section{The "not necessary" explanation}

The Australian guardianship tribunal process shares many of the advantages and benefits of the mediation process, namely the process is informal and flexible and is efficient and cost-effective. To an informed observer the conduct of an Australian guardianship tribunal hearing displays many similarities to mediation. Parties are given opportunity to speak, to hear other points of view and are not constrained by legal arguments. The informal and inquisitorial process allows the tribunals to employ procedural fairness techniques such as ensuring all parties have an opportunity to present their views and seeking feedback on possible outcomes of the proceedings. ${ }^{41}$ In deciding what orders will be in the

40 Ibid. at 640.

41 Presenting the results of a study of the Victorian Guardianship Board (now replaced by the Civil and Administrative Tribunal), Carney concludes that the objective of creating the Board, namely of creating an accessible, informal and expert decision making body "would also appear to have been met with a large measure of success," Terry Carney, "Client Assessment of Victoria's Guardianship Board” (1989) 15 Monash U.L. Rev. 229 at 251. 
best interests of the person with a disability the tribunal seeks to understand the underlying fears, concerns and needs of the parties rather than simply accepting their advocated positions. In this way the interests of the parties and relationship issues are taken into account to the extent possible in order to maximize the opportunity for supportive relationships for the elderly person. The focus is on a common problem about what is needed for the future - what decisions need to be made about and for a person with a disability, rather than accepting the positional view of one or other of the parties.

Tribunals may also conduct proceedings by focusing on the aspects of the case upon which the parties can agree and leaving to one side issues upon which they still disagree (particularly, as noted above, when the source of the conflict goes beyond issues concerning the person with a disability) and which do not require determination to dispose of the application. Tribunal members may use many of the skills of a mediator even though, ultimately, their role is determinative in nature once the need for appointment of a substitute decision maker has been established. The legislative mandate to conduct hearings in a timely and informal manner enables tribunal members to adapt the nature and focus of the proceedings to the application at hand. The tribunal hearing and mediation, therefore, have many features in common. The two most significant differences, identified in the Introduction, are first, that in a tribunal hearing the final decision remains with the tribunal member, not the parties and second, in mediation the parties can decide what issues they want to raise and address, whereas the issues in a hearing are determined by the nature of the application and by the tribunal.

Notwithstanding that mediation is used infrequently by tribunals and the reasons set out above that explain this, it is clear that there is scope for greater use of the mediation process to resolve issues and disputes concerning the elderly and other people with decision making disabilities. We turn now to examine when mediation can be used to advantage in conjunction with the tribunal system, and identify the issues that need to be addressed to ensure that mediation is used appropriately to resolve guardianship issues concerning the elderly.

\section{B. Aligning the benefits of mediation with the Tribunal process}

Mediation will be particularly beneficial where a dispute between family members or other interested parties is long standing and concerns an issue that does not need to be determined by the tribunal. Agreements that have the effect of reducing family conflict that is impacting upon an elderly person or that achieve a workable agreement between family members and a service provider may be beneficial to all concerned. In these circumstances the process has much to offer the elderly person. ${ }^{42}$ There may also be benefits of referring the parties to mediation even after an application has been made to the tribunal, particularly if

42 If the tribunal determines that it does not have jurisdiction or that there is no need for an appointment, the issues or disputes that sparked the application may remain unresolved. As Radford points out, mediation provides an opportunity for conflict resolution, in which parties recognize and deal with their incompatibilities and work together productively to manage them. See Radford, "Mediation Appropriate," supra note 10 at 641. 
it can avoid the need to appoint a guardian. It is helpful to distinguish between the following three stages of a guardianship matter at which mediation may be of benefit.

\section{Pre-application mediation}

This is the stage at which, arguably, there is the most scope for mediation. When the "least restrictive alternative" principle is applied at the pre-hearing stage by family members, carers, health professionals and tribunal staff, applicants are encouraged to find alternative means to the appointment of a guardian or administrator to resolve a particular issue. ${ }^{43}$ Appointment of a guardian or administrator is always a last resort. ${ }^{44}$ Where a less restrictive means in found, no application will be necessary or the applicant can be invited to withdraw his or her application. The investigative stage of guardianship proceedings during which alternatives are explored is likely to have a 'mediation effect' that is contributing to the low recorded numbers of matters mediated within the tribunal. Another explanation for the low number of matters needing to be mediated within the tribunals is that matters suited to mediation are already being mediated by health professionals in hospitals and aged care facilities. ${ }^{45}$

Mediation at this stage requires the provision of appropriate mediation services as a first step to resolving disputes in relation to an elderly person with a decision-making disability. The benefits of mediation at this stage are that it might result in a less restrictive alternative and negate the need for orders, or at least reduce the issues that need to be addressed by a hearing and orders.

\section{Post-application mediation}

Mediation can be used after the hearing process has begun. This might involve an adjournment with a follow up hearing, or mediation by a tribunal member with authority to make orders consistent with the settlement terms agreed to by the parties in mediation.

\section{Post-appointment mediation}

Mediation after the appointment of a guardian or administrator can address some of the issues that require decisions to be made, such as the management of an elderly person's assets prior to their death or schedules for visiting the elderly person at home or in a care facility. In this scenario the authority to

43 The benefit of mediation resulting in a less restrictive alternative is noted by Senator Gordon H. Smith, Ranking Member, United States Senate Special Committee on Aging, and Senator Herb Kohl, Chairman, United States Senate Special Committee on Aging, in their paper "Guardianship for the Elderly: Protecting the Rights and Welfare of Seniors with Reduced Capacity," December 2007. online: National Aging in Place Council <http://www.naipc.org/ Portals/0/_pdf/Senate\%20Report_Guardianship\%20of\%20Elderly.pdf>, (Accessed 27 January 2009).

$44 \operatorname{Re} M \& R$ \& The Guardianship and Administration Board (1987) 2 VAR 213 at 219. This was a decision of the President of the Administrative Appeals Tribunal (Vic), his Honour Judge Jones.

45 Dr. Bev Ferres, Geriatrician, Bendigo Health Care Group, Australia and a delegate to the Australian Guardianship and Administration Conference, Brisbane 19-20 March 2009, offered this explanation to the authors, 20 March 2009. 
mediate emanates from the appointment, and the question of authority to reach agreement in mediation is conferred upon the administrator or guardian by the appointment. ${ }^{46}$ Similarly, when a tribunal appoints an independent statutory authority to act as guardian or administrator, there is scope for the appointee to engage the parties in mediation or in other consultative and facilitated decision making processes to promote the best interests of the incapacitated person into the future. In many cases, a guardian or administrator may informally "mediate" between parties after they have been appointed, with a view to achieving consensus in decision making even though ultimately they have the legal authority to make a final decision.

\section{Mediation of guardianship issues - issues to be considered}

Assuming issues or disputes concerning an elderly person with a disability are capable of being mediated, a number of issues require consideration. ${ }^{47}$ While this article identifies these issues in a summary manner, further analysis is warranted. ${ }^{48}$ There is recognition that, as the practice of elder mediation grows, there is a need to develop practice guidelines and develop mediator competencies. ${ }^{49}$ Although the focus in this article is on implications for tribunals, similar and additional practice and ethical issues arise for mediators asked to determine whether mediation is a suitable process to resolve issues relating to an elderly person's lack of decision making capacity outside the guardianship tribunal system. ${ }^{50}$

\section{Compulsory mediation?}

Increased use of mediation within court and tribunal systems has been achieved in a number of jurisdictions by making mediation 'compulsory' or "mandatory." While this suggests that all matters must be mediated, in reality it means that all matters must be considered for mediation, and, in some cases,

46 It can be argued that a substitute decision maker cannot truly stand in the shoes of represented person in mediation. Taking too strict a view of this question may, however, deny the represented person the opportunity to benefit from mediation, Wood, supra note 10 at 816 . In each case the appointed decision maker will need to assess the benefits of the process for the person for whom they are a substitute and how they can make the best of their participation in the mediation.

47 Others have identified a similar need for further exploration. See e.g. Israel Doron, "Mental Incapacity, Guardianship and the Elderly: An Exploratory Study of Ontario's Consent and Capacity Board" (2003) 18 C.J.L.S. 132.

48 For a similar view and a list of issues requiring closer consideration of mediation of elder law issues, see Kathryn Mariana, "Briefing on the First National Symposium on Ethical Standards for Elder Mediation” (2007) 28 Bifocal: Bar Associations in Focus on Aging and the Law, 75 (Part I), 85 (Part II), at 90.

49 See e.g. the Canadian Centre for Elder Law "Elder and Guardianship Mediation Project, (2009)" funded by British Columbia Law Institute. The Project is "gathering pertinent research and consulting key stakeholders in order to provide information essential for both the adoption of mandatory mediation in British Columbia, and for mediators who work with older clients" online: Canadian Centre for Elder Law <http://www.bcli.org/ccel/projects/elder-andguardianship-mediation> (accessed 28 April 2009).

50 See Schmitz, supra note 10; More generally, see Sharon Flower, "Resolving Voluntary Mental Health Treatment Disputes in the Community Setting: Benefits of and Barriers to Effective Mediation" (1998-1999) 14 Ohio St. J. Disp. Resol. 881. 
that parties are required to participate in the mediation process. ${ }^{51}$ There is clear judicial recognition that while participation can be mandated, agreement making as a result of participation in the process cannot. ${ }^{52}$ Increased participation in mediation has been achieved in Australia by introducing mediation as a prefiling requirement ${ }^{53}$ and by diverting all filed applications into mediation before proceeding to a hearing. ${ }^{54}$ Whichever approach is adopted, provision needs to be made for excluding unsuitable cases from mediation. ${ }^{55}$ Further, any mandated mediation scheme needs to ensure that quality mediation services are available to the parties who are unable to access the hearing process. In the guardianship jurisdiction in Australia this would involve a significant redeployment of resources.

\section{Process choice - screening for suitability}

Numerous factors are relevant to determining whether or not the mediation process is suited to a particular guardianship issue or dispute. ${ }^{56}$ While a decision making disability will affect a person's ability to participate in the process and agree to an outcome and therefore is a major limiting factor, it is not conclusive of the question whether mediation will be of benefit to them. ${ }^{57}$ There are many process strategies, discussed below, that can be adopted to enhance the ability of a person with a disability to participate in the mediation process. Further, a lack of decision making capacity by a person the subject of a guardianship application does not preclude mediation between parties other than the person with

51 There are numerous statutory provisions that require parties to participate in mediation. See Spencer \& Brogan, supra note 2, at Chapter 8 for Federal and State legislative examples.

52 Hooper Bailie Associated Ltd v Natcon Group Pty Ltd (1992) 28 NSWLR 194; Aiton Australia Pty Ltd v Transfield Pty Ltd (1999) 153 FLR 236, per Einstein J at 250: "What is to be enforced is not cooperation and consent but participation in a process from which consent might come."

53 Most notably in family law proceedings, see the Family Law Act 1975 (Cth), s. 60I. For discussion of the meaning of "genuine effort" and "good faith" requirements to mediate, see Hilary Astor, "Making a Genuine Effort in Family Dispute Resolution: What Does it Mean?" (2008) 22 Austl. J. Fam. L. 102.

54 See Boulle, supra note 2, at 374 for discussion of case management principles as applied to mediation and of criteria relevant to court referrals.

55 S. 60I(9) of the Family Law Act 1975 (Cth) provides a number of exceptions to the requirement to use family dispute resolution (which includes mediation), including where there are reasonable grounds to believe there is abuse or risk of abuse to a child, or family violence or a risk of family violence, (s. 60I(9)(b); where there is urgency, (s. 60I(9)(d); and the inability of one of the parties to participate effectively in the process, s. 60I(9(e)), for example because of incapacity of some kind. Further provision for determining whether family dispute resolution is appropriate is made in the Family Law Regulations. Regulation 62 (2) requires a practitioner to be satisfied that consideration has been given to whether the ability of the parties to negotiate freely is affected by a number of factors, including the equality of bargaining power among the parties, $((62)(2)$ c); and the emotional, psychological and physical health of the parties, $(62(2)$ (e); and any other relevant matter, (62(2)(f)).

56 See, for example, Australian Law Reform Commission (ALRC), Managing Justice: A Review of the Federal Civil Justice System, Report No 89, 2000, at [6.62] where factors indicating that ADR processes are unsuitable for resolving a dispute are set out. Generally see Spencer and Brogan, supra note 2 at 42-48. For discussion of suitability factors in guardianship matters see Carroll, "Appointing Decision Makers," supra note 10 at 83.

57 Simpson, supra note 10 at 33. 
a disability in appropriate circumstances. It may well be the case that reaching an agreement can avoid the need for an appointment of a guardian to be made. There is also potential to mediate the evidence of experts, especially on the issue of capacity, and to narrow the issues needing to be determined.

Screening for suitability of mediation in guardianship matters could be done by external agencies before an application is brought or within the tribunal registry after an application has been made. While decisions about suitability could be made by a tribunal member after a review of the paper application, in the authors' view it would be preferable that the decision be made following a directions hearing, ensuring an opportunity for parties to make submissions on suitability. In many instances this would involve an additional procedural step but still result in most applications proceeding to hearing. In the absence of a funded mediation service outside the tribunal for matters of this nature, mediation is likely to be provided by the tribunal. If a tribunal member conducts the mediation the question inevitably arises whether the mediation process is more appropriate than proceeding straight to a hearing.

\section{Process strategies}

Where mediation is suitable, there are many ways that a mediator can assist one or more of the parties to participate effectively and to their full capacity in the mediation process. ${ }^{58}$ Similarly, there are a number of ways to adjust the ADR process to avoid a person with a disability being disadvantaged. ${ }^{59}$ Simpson advocates looking at ways of ensuring that the disabled person is able to participate in the process. ${ }^{60} \mathrm{~A}$ hallmark of mediation is the flexibility of the process to allow for strategies like ensuring the meeting room is informal and free of distractions, ensuring clear explanations are given and incorporating frequent breaks. Other approaches identified by Simpson are to provide the person with an advocate or a support person and to rely, in part at least, on the other parties to adequately protect the interests of the person with a disability. ${ }^{61}$ In a guardianship matter this may involve family members and service and care providers. In addition, there are many ways in which the choice of mediator, the role they play and the skills they exercise in a statutory context can be adapted to ensure that the mediation process is appropriate and effective. ${ }^{62}$ This is particularly important in a jurisdiction which aims to protect the person with a disability and at the same time to uphold statutory principles of autonomy.

\section{Which model of mediation is appropriate?}

There are a variety of models of mediation, including facilitative, evaluative,

58 National Alternative Dispute Resolution Advisory Committee, A Fair Say: Managing Differences in Mediation and Conciliation: A Guide for All Involved, (Canberra: NADRAC, Barton ACT, 1999), which sets out examples of the barriers that elderly adults and people with disabilities might face and ways to break down barriers for them in mediation, at 21, 23 .

59 Simpson, supra note 10 at 33-39.

60 Ibid. at 33.

61 Ibid. at $34,35$.

62 Claire Baylis \& Robyn Carroll, "The Nature and Importance of mechanisms for Address Power Imbalances in Statutory Mediation” (2002) 14 Bond Law Review 285. 
and transformative mediation. ${ }^{63}$ Facilitative mediation is process-oriented and a problem solving approach in which the parties rather than the mediator provide the solution to their dispute. The mediator is the facilitator of the process rather than an authority figure providing substantive advice or pressure to settle. Evaluative mediation is substance orientated mediation, at the other end of the scale from facilitative mediation. The mediator is often an authority figure who evaluates the case based on his or her experience and offers advice on how the dispute could be resolved. In transformative mediation the emphasis is not on problem solving but on the nature of the process itself. In this model, the mediator's role is to foster empowerment and recognition in the parties; this is done by encouraging the parties to communicate and make decisions more effectively, subject to their own choices and limits.

Facilitative and evaluative mediation can both be described as forms of settlement mediation. The primary goal of these processes, particularly when employed in a court or tribunal setting, is settlement of the legal dispute. This is not to say that there are no therapeutic benefits of the process, whether through improved communication and understanding between the parties, or through the outcome of the mediation where there is resolution of all or part of a dispute. In contrast, settlement is not the primary goal in transformative mediation.

When contemplating which model of mediation is appropriate, consideration needs to be given to the distinctive nature of the guardianship jurisdiction. Guardianship disputes and applications differ from most private law disputes where the aim of the proceedings is to settle a dyadic dispute. An adult guardianship case is, as pointed out by Radford:

neither a traditional legal dispute not is it dyadic. The outcome of an adult guardianship case is crucial primarily (and arguable only) to the individual who is the focus of the case. Unlike litigation, in which two or more parties have competing interests at stake, the only individual whose interest is at stake in an adult guardianship case is that adult. ${ }^{64}$

Which model is appropriate will depend on the purpose of the mediation. If it is to achieve an outcome that will avert the need for a guardianship order then any form of settlement mediation will serve that purpose.

In tribunal jurisdictions other than guardianship, a mediation-arbitration model holds some attraction. Using this model the mediator and parties agree that they will first attempt to reach agreement using the mediation process. The parties also agree that if no agreement is reached the mediator will assume a determinative role and, based on what has been discussed in the mediation, decide the matter. This model requires that the mediator has the power to determine the matter. In Australia this usually means they must be a tribunal member. Although this model is suited to legal disputes where the parties have authority

63 For discussion and analysis of the various models of mediation, see the texts referred to in supra note 2 .

64 Radford "Mediation Appropriate," supra note 10. 
to settle, it will have limited application to guardianship matters because of the nature of the orders made by guardianship tribunals.

Mediation conducted within a statutory framework faces a number of challenges; definitional, process and substantive. How can statutory principles applicable to a particular dispute be observed within a party controlled process? As Simpson notes, one way that the rights and interests of people with disabilities can be protected where ADR occurs in the context of legislation is to impose on the mediator a duty to ensure that statutory principles are upheld. ${ }^{65}$ The process where the "mediator" exercises an advisory role within a facilitative process is often referred to as conciliation, although the overlap in features of mediation and conciliation makes it difficult to draw any clear distinction between the two processes. In all likelihood, mediation within a tribunal setting will involve the mediator undertaking their role guided by the statutory principles, even though the process is facilitative and not advisory. In a similar way that family dispute resolution practitioners are bound to ensure that the process is appropriate in light of the best interest of the child principle in children's matters ${ }^{66}$ so too in guardianship matters will the best interests of the person with a disability need to guide the process and any outcomes.

There is greater potential for the use of a facilitative process within the tribunal where an additional process step ensures that the public interest has been met by the outcome agreed upon in mediation. A recent report on a process used by the State Administrative Tribunal (SAT) of Western Australia in vocational matters could potentially be adapted to guardianship matters. In the vocational stream within the SAT, vocational bodies previously usually prosecuted and heard the matters allowing little or no opportunity for the parties to discuss the matter with a view to resolving it prior to any hearing. Increasingly, these matters are now dealt with using mediation. Spillane reports that:

When the Tribunal was first introduced and the prospect of mediation in vocational matters was raised, many parties were highly skeptical that such disputes could be resolved by any means other than a hearing. However, history has now shown an entirely different story and, in the writer's view, it is one of the real success stories of the Tribunal to date, saving enormous amounts of time and cost, not to mention stress for the parties involved. One must emphasise that even though the Tribunal has been successful in facilitating resolutions in a large majority of vocational matters without the need for a final hearing, the Tribunal is very cognisant of the high public interest in these matters and the need to ensure transparency. For this reason, if parties to a vocational matter agree terms to finalise the matter, two things must happen

65 Simpson, supra note 10 at 38.

66 Family Law Regulations 1984 (Cth) Regulation 64(c)(ii) requires a family dispute resolution practitioner to terminate the family dispute resolution if they are no longer satisfied that family dispute resolution is appropriate. 
before the Tribunal will make the orders requested. These are:

1.The mediator must be satisfied that, in the circumstances of the case, the penalty being agreed to is within an acceptable range, keeping in mind other matters of a similar nature that have been before the Tribunal. If the member is not satisfied with the agreed outcome, the matter will be listed before a panel on agreed facts for what is essentially a hearing on penalty.

2.There is full public disclosure in the Tribunal's final orders of the identity of the practitioner, the facts of the case, the allegations put, the admissions made and the penalty agreed and there is no suppression of any of the matters involved. The order setting out all of these issues is then published on the Tribunal's web site. ${ }^{67}$

While the public disclosure aspect of this SAT process is not appropriate to guardianship matters, there is some scope for guardianship matters to be adapted in a similar way so that the statutory guardianship principles are maintained as well as orders being made where necessary.

\section{Legal, ethical and practical issues for mediators}

The key issues likely to arise in mediation concern the capacity of parties to participate in the process, difficulties of assessing capacity resulting from laws of privacy and confidentiality of information concerning the elderly person and the propriety of agreements reached in the absence of capacity of the elderly person and/or full information about their capacity.

\section{(a) Disclosure of medical assessments and information}

The threshold question of capacity is usually determined by relying on private and confidential medical evidence. Sometimes the tribunal concludes that it in the best interests of the person to whom the evidence relates that the information be disclosed to the parties to an application. At other times, however, there will be information that the tribunal does not believe should be disclosed to the parties. Withholding this information in a hearing setting does not impede the ability of the tribunal to adjudicate on the application before it. It will, however, have significant implications for the mediation process if it prevents the parties reaching a fully informed agreement. Even greater difficulty will be encountered in mediation conducted outside the tribunal as neither the mediator nor the parties will be legally entitled to obtain information concerning the elderly person essential to resolving questions of capacity and deciding on appropriate action in the future. Were private or confidential information to be obtained by the parties to mediation in circumstances where the mediator was aware that the elderly person may lack capacity to consent to its disclosure, the mediator would be bound to terminate the mediation.

67 Spillane, supra note 7 at 5-6. 
Where an elderly person whom an application concerns is present during a hearing their views are usually sought if they are willing and able to communicate them. His or her presence at a hearing, where it would not be detrimental, is likely to be important to the integrity of the proceedings. The presence, however, of the elderly person for all or part of the hearing, does not preclude the tribunal reaching a decision that is inconsistent with his or her expressed wishes. The tribunal, exercising powers conferred on it by legislation, is bound to give effect to statutory guardianship principles. In mediation, the mediator and parties may wish to involve the elderly person in the process but lack medical information to ensure that participation is appropriate. In addition, assessment of a person's decision making capacity requires a level of expertise and experience. A person may present in a competent manner in relation to simple decisions but lack capacity to make more complex decisions. ${ }^{68}$ Capacity can fluctuate and is affected when a person is under stress. ${ }^{69}$ As a result a person may, for example, be able to make reasonable decisions during a brief discussion yet be incapable of sustaining this capacity for the duration of a hearing or mediation session. ${ }^{70}$ This poses a challenge for mediators who need to ensure that agreements made in mediation are made voluntarily by parties who have capacity to agree. ${ }^{71}$

\section{(b) Improper Agreements}

As there are limits to the matters on which parties can make effective agreements, a mediator will need to know when it is necessary to terminate the mediation. For example, family members are not entitled to agree between themselves to distribute inter vivos the property of an elderly person who no longer has the capacity to manage his or her own financial affairs. Nor are they entitled to appoint one or more family members to take over a decision making role for the elderly person as the agreement would have no legal effect. Potentially even more complex, is the responsibility of a mediator to ensure that any agreement reached in mediation relating to the personal and financial well being of a person they know or suspect to lack capacity satisfies the best interest principle and other principles enshrined in guardianship legislation. In each of these cases, were the mediator to have concerns, the only course of action open to them in most cases would be to terminate the mediation. Concerns might persist however that agreements would be made outside the mediation which would not serve the interests of the person who lacks capacity.

68 New South Wales Government, Attorney General's Department Capacity Toolkit, 2008, section 2. online: NSW Government <http://www.lawlink.nsw.gov.au/Lawlink/DiversityServices/ ll_DiversitySrvces.nsf/pages/diversity_services_capacity_toolkit> (accessed 27 April 2009)

69 Ibid.

70 Ibid.

71 Radford "Mediation Appropriate" supra note 10 at 649-650 sets out guidelines available for determining whether the parties to mediation have capacity, including the ADA Mediation Guidelines available online: Cardozo Journal of Conflict Resolution <http:/www.cojcr.org/ ada.html> (last accessed 13 March 2009) or Mediate <http://www.mediate.com/articles/adaltr. cfm> (last accessed 13 March 2009); and Hartman supra note 17. See also Gary, supra note 10 at 442 . 


\section{(c) Additional Concerns}

There are many practical issues that will accompany increased referral to mediation of matters that presently are brought before guardianship tribunals. For example, who should attend the mediation? Where a hearing is conducted it is possible to include a wide range of interested parties because they do not have any say in the final decision and there are legislative restrictions upon disclosure of the identity of the persons involved in the proceedings. It may well be appropriate to apply the same approach to mediation even though the same legal consequences are not attached to disclosure. Finally, timeliness and cost factors will be significant in deciding whether it is practicable to address the issues arising out of an application through mediation or by a hearing.

\section{Mediator training and expertise}

More frequent use of mediation in the tribunal setting inevitably raises questions about appropriate training of members as mediators and the standards of practice to which they must adhere. Tribunals will need to follow developments in mediation standards in Australia and the introduction of a mediator accreditation process. ${ }^{72}$ One issue to be addressed is whether tribunal members have the appropriate training and experience to mediate the types of family conflict that often underlie the disputes that surface when a guardianship application is before the tribunal. ${ }^{73}$ The same issue, with the additional questions of accountability and redress in the event that acceptable standards are not met, arises when private mediators are involved.

\section{Resource issues}

The conclusions presented in this article are generalized and do not expressly take into account the circumstances in any particular jurisdiction within Australia and the influence of the local guardianship culture. The more established

72 A National Mediator Accreditation System was introduced in Australia at the beginning of 2008. The Australian National Mediator Practice Standards for mediators operating under the National Mediator Accreditation System (NMAS) were published in 2007 and are available online: LEADR <http://www.leadr.com.au/documents/Practice\%20standards.pdf> (last accessed 13 March 2009). Background papers to the Standards are available online: Western Australian Dispute Resolution Association (WADRA) <www.wadra.law.ecu.edu.au> (last accessed 13 March 2009). A National Mediator Accreditation Committee, supported by the National Alternative Dispute Resolution Advisory Committee (NADRAC) has been established to implement the NMAS and establish a permanent National Mediators Standard Body in 2010.

73 Accreditation standards have been introduced for family dispute resolution practitioners. Under the Family Law (Family Dispute Resolution Practitioner) Regulations 2008, accredited practitioners mediating children's issues under the Family Law Act 1975 (Cth) will need to meet training and practice standards from 1 July 2009. The new standards include specific competencies for all family dispute resolution practitioners, which include: responding to family and domestic violence in family work; creating a supportive environment for the safety of vulnerable parties in dispute resolution; and, operating in a family law environment. For requirements application to family dispute resolution practitioners See online: Australian Government: Attorney-General's Department <http://www.ag.gov.au/www/agd/agd.nsf/ Page/Families_FamilyRelationshipServicesOverviewofPrograms_ResearchandEvaluation_ ForPotentialFamilyDisputeResolutionPractitioners $>$. 
and well resourced are the mediation services in a particular jurisdiction, the more likely it is that mediation can be used to complement, if not replace, tribunal proceedings.

Higher levels of funding for mediation to be conducted by publicly funded bodies like the Public Guardian could reduce the amount of applications brought to the tribunal and consequently the number of substitute decisionmaking orders made. Similarly, greater awareness within the community of the benefits of mediation, access to quality mediation services and preparedness of family members to use mediation all have a part to play in diverting suitable matters to mediation instead of, or in addition to, applications to tribunals for orders.

\section{CONCLUSION}

Mediation has an important role to play in the resolution of conflict and disputes relating to the elderly and others with decision making disabilities. This is particularly the case where the resolution of family conflict and consensual decision making can provide a less restrictive alternative to an order, (pre-application mediation) or can ensure the smooth operation of guardianship or administration (post-appointment mediation). Parties can be assisted to focus on the interests of the elderly person and to address some of the underlying causes of conflict between the parties. Guardianship tribunals can play an important role in educating the public about these benefits. We conclude, however, that the informal and inquisitorial nature of the guardianship application and hearing process has largely rendered an "alternative" approach to dealing with applications unnecessary from the perspective of costs or timeliness and from a therapeutic perspective. While there is some scope for mediation of matters where an application has been made, (post-application mediation) in the majority of cases it is unlikely to be necessary as a substitute for a tribunal hearing. We also conclude that mediation will often be unsuitable due to the nature of the jurisdiction and the need in many cases for the legal appointment of a decision maker for a person with a decision making disability. Where mediation is used, a number of legal, ethical and process issues require careful consideration. The potential benefits to the elderly, however, calls for further exploration into the use of mediation to assist parties who are concerned with the welfare of an elderly person with a decision making disability. 